\title{
NOTAS PARA UM CÂNONE (NADA) COR-DE-ROSA: O RESGATE DA PRODUÇÃO DE AUTORIA FEMININA E SEU PAPEL NO ENSINO E NA LEITURA DE LITERATURA EM SALA DE AULA
}

\author{
NOTES TO A (NO) PINK CANON: THE RETRIEVAL OF \\ FEMALE AUTHORSHIP AND YOURS ROLE ON LITERARY \\ TEACHING AND READING IN CLASS ROOM
}

\author{
Rafael Eisinger Guimarães \\ Universidade de Santa Cruz do Sul, UNISC, Santa Cruz, RS, Brasil
}

\begin{abstract}
Resumo: Este artigo apresenta uma discussão sobre o resgate da literatura de autoria feminina, problematizando as premissas dos discursos crítico e historiográfico que sustentam o cânone literário brasileiro. A partir das questôes propostas por Rita Terezinha Schmidt, Antoine Compagnon, Toril Moi, Luiza Lobo, Jaime Ginzburg, Douwe Fokkema e Elrud Ibsch, dentre outros, é feita uma reflexão sobre o papel emancipatório da educação, articulando-se as concepções apresentadas com uma postura docente voltada à formação de leitores críticos, em especial no que diz respeito ao silenciamento das mulheres no processo de narração da nação.
\end{abstract}

Palavras-chave: Autoria feminina; Crítica feminista; Cânone literário; Educação.

Abstract: This essay presents a discussion about the retrieval of female authorship literature, problematizing the assumptions of the critical and historiography discourses that underpin the Brazilian literary canon. From the questions proposed by Rita Terezinha Schmidt, Antoine Compagnon, Toril Moi, Luiza Lobo, Jaime Ginzburg, Douwe Fokkema and Elrud Ibsch, among others, it is made a reflection on the emancipatory role of education, articulating the concepts presented with a teaching position focused on the formation of critical readers, in particular with respect to the silencing of women in the process of narration of the nation.

Keywords: Female authorship; Feminist criticism; Literary canon; Education.

O livro, a leitura e o ensino de Literatura, afirmam alguns, são dinossauros em franca e dolorosa agonia. A obra literária em papel, objeto de encantamento e veneração, já se depara, há alguns anos, com a "ameaçadora" presença do seu "outro" digital, o qual, por sua vez, também náo parece estar conseguindo vencer a guerra contra a pouca valorização do ato de ler. Por seu turno, verifica-se que a disciplina de Literatura, em sintonia com essa realidade, tem perdido espaço considerável tanto na esfera do Ensino Básico quanto no âmbito dos cursos de licenciatura em Letras. $\mathrm{O}$ leitor contemporâneo, que se encontra imerso em um mundo regido pelo imediatismo e pela interatividade das tecnologias digitais, bem como o aluno 
de Ensino Médio do século XXI, que nasceu em um contexto marcado pela ideia do eterno presente hipermoderno (LIPOVETSKY, 2004), por razóes que me parece desnecessário explicitar aqui, veem o livro, a leitura e as aulas de Literatura de forma distinta daquela que nós, professores e pesquisadores da área, pensamos que deveriam ser vistos e compreendidos.

Náo obstante o fato de vivermos sob o signo da volatilidade e da liquidez, como quer Zygmunt Bauman (2001), a facilidade de acesso à informaçáo e o caráter das relaçóes contemporâneas, construídas e consolidadas no espaço das redes sociais digitais, fazem ressurgir, com novas tintas, debates e demandas que pareciam apagados ou, como é o caso da crítica feminista, davam a impressão de estarem restritos ao lado de dentro dos muros acadêmicos. Nesse sentido, movimentos e campanhas como o "Vamos Juntas"1, "\#primeiroassédio"2, "Lendo Mulheres", dentre outras açôes surgidas e divulgadas no espaço da internet, parecem reforçar o diagnóstico de Constância Lima Duarte (2003) contido na afirmação de que, apesar de algumas vozes defenderem o argumento de que vivemos a era do "pós-feminismo", muitas reivindicaçóes das mulheres ainda não foram atendidas (como a persistente desigualdade de salários e cargos entre os gêneros, a escassa presença das mulheres nos espaços de decisão públicos e empresariais, os alarmantes índices de violência doméstica e sexual, entre outras questôes), sinal claro da permanência e da força de muitos nichos patriarcais, em especial nas instâncias que lidam com o simbólico e com o imaginário, como é o caso do cânone literário e da forma como este é abordado em sala de aula.

Diante de tal cenário, repensar como a Literatura Brasileira é ensinada e discutida na educaçáo básica, em especial no que tange à questáo do cânone literário, torna-se uma tarefa urgente e crucial, uma vez que, como assinala Rita Schmidt (2008b), a abordagem conservadora e elitista que predomina tanto no Ensino Médio quanto nos cursos de licenciatura em Letras "compromete o alcance do próprio ensino-aprendizagem em sua dimensão emancipatória e limita o docente à repetição de uma concepção monolítica da cultura que aborta o alcance de seu papel como agente de formação, produção e transformação" (SCHMIDT, 2008b, p. 51). Em vista disso, pretendo, neste ensaio, refletir acerca da importância do resgate das obras literárias de autoria feminina, em especial as produzidas no século XIX, que foram silenciadas por um discurso crítico e por uma historiografia

\footnotetext{
${ }^{1}$ Disponível em: <http://www.movimentovamosjuntas.com.br/>. Acesso em: 20 mai. 2017.

${ }^{2}$ Disponível em: <http://thinkolga.com/>. Acesso em: 20 mai. 2017.

${ }^{3}$ Disponível em: <http://www.lendomulheres.com.br/>. Acesso em: 20 mai. 2017.
} 
marcados pelo pensamento patriarcal. Mais do que retomar as ideias de figuras renomadas, que discutiram em profundidade questôes como o papel da Literatura, o processo de formação do cânone e a violência simbólica que permeia a atribuição de valor a algumas obras literárias em detrimento de outras, o objetivo aqui é articular essas reflexôes com uma concepção emancipatória de educação, que almeje a transformação das alunas e dos alunos, seja no nível básico, seja no nível superior, em leitoras e leitores críticos.

\section{Do silenciamento à subversão: a problematizaçáo do cânone literário a partir da autoria feminina}

O não tão recente debate em torno da importância da Literatura, em parte decorrente da perda de espaço dessa disciplina no âmbito educacional, reacendeu o sentimento - talvez real, talvez ilusório - de que o literário, como instituição, como prática e como campo do saber, necessita ter o seu valor e a relevância do seu papel defendidos, sob pena de deixar de existir. Diversas manifestaçóes nesse sentido tomaram corpo e ganharam visibilidade na área das ciências humanas, em especial a antológica postura de Roland Barthes (2004), na qual ele assevera que, no caso de todas as disciplinas deixarem de existir, a Literatura é a única que deveria ser salva. Quase 30 anos depois, e no mesmo espaço onde seu conterrâneo pronunciara tais palavras, Antoine Compagnon (2012) assume o papel de advogado da arte da palavra. Em seu Literatura para quêe, ele, a partir de uma perspectiva um tanto quanto distinta da apresentada na Aula, de Barthes, observa que apoética e a historiografia- aquela levando em conta o valor eterno e universal do literário, visto de forma sincrônica em sua singularidade, esta tomando a obra em uma perspectiva diacrônica, distante no tempo e no espaço - são formas distintas de abordagem da Literatura como objeto de estudo, mas a crítica é a razão de ser do ensino da Literatura. Nesse sentido, valendo-me das palavras de Antoine Compagnon (2012), é possível dizer que "ao lado da pergunta tradicional [...] 'que é a literatura?', questão teórica ou histórica, coloca-se hoje mais seriamente a pergunta crítica e política: ' $\mathrm{O}$ que a literatura pode fazer?' Em outras palavras: 'Literatura para quê?'” (p. 28). Ao discutir as razóes pelas quais ainda lemos, a despeito das reiteradas declaraçôes acerca do "fim do livro", o pensador francês busca responder a essa pergunta, sublinhando um saber insubstituível e exclusivo da Literatura, algo que apenas ela pode dizer sobre a natureza humana, devendo, portanto: 
[...] ser lida e estudada porque oferece um meio - alguns dirão até único - de preservar e transmitir a experiência dos outros, aqueles que estão distantes de nós no espaço e no tempo, ou que diferem de nós por suas condiçốes de vida. Ela nos torna sensíveis ao fato de que os outros são muito diversos e que seus valores se distanciamdos nossos (COMPAGNON, 2012, p. 60).

Nesse sentido, insiste o referido pensador, a leitura literária e, por extensão, o seu ensino justificam-se, sobretudo, por oferecerem representaçóes coletivas e propiciarem uma educação sentimental que nos torna mais sensíveis e críticos em relação às questôes da identidade e da alteridade. Encaminhando o seu pensamento pela mesma seara, Toril Moi (2009), ao discutir o texto "O que pode a literatura?", de Simone de Beauvoir, propóe indiretamente um aprofundamento das questóes levantadas por Compagnon. Segundo ela, a Literatura revela o mundo aos seres humanos, a partir de um ponto de vista específico - o do autor -, determinado por sua experiência de vida, que é, por óbvio, marcada pelo gênero. Em tal perspectiva, segundo Moi (2009), para Beauvoir, a Literatura de autoria feminina oferece um saber específico, um conhecimento a respeito da situação da mulher em um mundo sexista. Assim, "by writing, women convey the unique taste of their own lives. By reading their work, Beauvoir can, for a moment see the world as they see it without losing her own identity" (MOI, 2009, p. 196).

Como parece estar claro, longe de ser um espaço de certezas, as obras literária configuram-se como locus da inquietaçâo, da dúvida e da problematização de concepçóes homogêneas e monolíticas. Se for aceitável a ideia de Compagnon (2012, p. 66) de que "a literatura é um exercício de pensamento", ou ainda, apropriando-me das palavras proferidas por Roland Barthes em sua aula inaugural, proferida em janeiro de 1977, no Collège de France, de que é possível entender o texto literário como uma manifestação da "língua fora do poder, no esplendor de uma revolução permanente da linguagem" (BARTHES, 2004, p. 16), torna-se bastante claro o potencial emancipatório dessa área do conhecimento, aspecto ressaltado pelo pensamento de Rita Schmidt (2008b, p. 59), que concebe o literário como um "território inquietante e instigador que expressa em suas formas os matizes dos conflitos, das tensôes e das diferenças que nos constituem como a comunidade imaginada da nação. Por isso, a literatura constitui, por excelência, um lugar de educaçáo para a alteridade".

A consciência da proximidade existente entre o processo de formaçáo e consolidação da identidade nacional e a produção de Literatura Brasileira, tanto no que se refere às obras escritas quanto ao discurso crítico acerca 
delas, bem como o papel desempenhado pelo cânone nesse processo, foi um dos eixos norteadores das investigaçóes levadas a cabo por Rita Schmidt, juntamente com as demais pesquisadoras que estiveram, desde 1985, à frente do Grupo de Trabalho Mulher e Literatura, da Associação Nacional de Pós-Graduação em Letras e Linguística (ANPOLL). Vale referir que esse trabalho teve, como uma de suas contribuiçóes mais relevantes, o resgate de uma extensa produçáo de autoria feminina oitocentista silenciada pela historiografia (MUZART, 2000b; 2004). Como bem ressalta Schmidt (2008b), por trás dessa íntima relação, está o projeto de "uma representação idealizada da cultura [nacional], como se esta constituísse uma totalidade sem fissuras" (SCHMIDT, 2008b, p. 50), uma concepçáo homogênea e elitista da Literatura e da identidade nacional que, como bem lembra a pensadora (SCHMIDT, 2000), perdura até os dias atuais e na qual ambas as instâncias se articulam na construçáo de um imaginário e um discurso pedagógico que excluem as mulheres e silenciam sua produçáo intelectual e literária. Similar é a constatação a que chega Regina Dalcastagnè (2010) ao analisar dados que revelam um significativo desequilíbrio entre as produçôes literárias de autoria masculina e feminina no cenário da literatura brasileira das últimas décadas ${ }^{4}$.

Longe de ser um processo gratuito e isento, a construçáo do cânone literário brasileiro e a consolidação do pensamento crítico que o sustenta dentro e fora do âmbito educacional revelam-se fortemente atravessadas por questóes de gênero, uma vez que tanto a elaboraçáo do primeiro quanto a enunciação do segundo têm como sujeitos escritores e pensadores homens, constituindo o que Rita Schmidt (2008b) designa, apropriandose das palavras de Candido, como "literatura dos senhores" (CANDIDO apud SCHMIDT, 2008b). Na origem desse processo, está a concepção de literatura nacional desenhada pela chamada "Trindade Crítica" - Sílvio Romero, José Veríssimo e Araripe Junior -, a qual tomava, como critério definidor do caráter de "brasilidade" de uma obra, a presença de temas e de elementos nacionais, tendo, contudo, como parâmetro avaliativo, o padrão estético ditado pelos autores canônicos europeus.

Nesse contexto, é possível afirmar, filiando-me às ideias de Rita Schmidt (2008b), que o sistema literário brasileiro, tal como se apresenta em termos de cânone e de programas de disciplinas nos âmbitos do Ensino Básico e Superior, constitui um instrumento de dominação, um discurso

\footnotetext{
${ }^{4}$ Segundo o levantamento feito por Dalcastagnè (2010), entre os anos de 1965 e 1979, 82,8\% do total das obras publicadas foram escritas por homens. Esse percentual apresentou um pequeno decréscimo entre os anos de 1990 e 2004, embora a autoria masculina ainda fosse responsável por $72,7 \%$ do total de obras publicadas no Brasil no período.
} 
de manutenção de um saber e de um poder que, em larga medida, vai na contramáo daquilo que Barthes (2004) identificava como sendo um dos maiores poderes da linguagem literária. Nas palavras da crítica feminista, tal paradigma ratifica:

[...] a prerrogativa e o privilégio de definir o que conta como literatura, e mais, o poder de imobilizar um conceito de literatura ou de disseminar determinado valor literário, segundo critérios fixos e preestabelecidos, sem questionamentos, como se fossem categorias absolutas, não uma definição e um valor entre outras definiçóes e outros valores (SCHMIDT, 2008b, p. 55).

Tal processo de ratificação de um saber hegemônico e pretensamente homogêneo lança máo de mecanismos de exclusão com o claro intuito de promover o controle e o apagamento das diferenças e tensóes culturais, resultando em uma violência simbólica que marcou, e ainda marca, profundamente, geraçôes de leitores e estudantes. No bojo dessa discussão, Jaime Ginzburg (2012) sublinha a importância do debate e da problematizaçáo acerca dos critérios que orientam o juízo de valor da crítica acadêmica, apontando para algumas das estratégias adotadas para "naturalizar" o posicionamento conservador que regula esse processo, dentre as quais se destaca a ideia de que o valor da obra é algo inerente a ela e não uma decorrência do olhar de quem a aprecia e julga. Contudo, lembra ele, a própria premissa de um valor universal e intrínseco ao objeto literário está estruturada em um discurso que, longe de ser isento, deixa transparecer uma forte carga de autoritarismo. Nas palavras do crítico:

A noção de universalidade de valor, em si mesma, mereceria longa e dedicada reflexão, atenta às vertiginosas implicaçôes do emprego essencialista da palavra "universal". [...] O emprego dessa palavra pede explicitação do ponto de vista de sua enunciação: a que universo nos referimos, a cada vez que dizemos essa palavra? Estaria o responsável pela enunciação projetando o universo a partir de si mesmo, modelando seus limites a partir de seus interesses específicos? [...] Podemos afirmar que uma obra é profunda, ou que ela provoca reflexão, como um modo de elogiar ou registrar seu poder de impacto; mas ao mesmo tempo, nấo estamos indicando nada específico. É possível sugerir que um estudo de lógica formal seria capaz de medir exigências reflexivas de um texto, como fazem abordagens empíricas, mas isso não permitiria mensurar o valor, como se fosse uma substância em seu interior - o valor é uma atribuição historicamente construída. Frases como "esta obra tem densidade" não são objetivas e evocam primariamente os interesses dos sujeitos que as enunciam (GINZBURG, 2012, p. 45-46). 
Considerando-se válida essa percepção de que, a despeito do seu verniz de universalidade, a ideia de valor como algo inerente à obra literária possui um locus de enunciação bem delimitado - masculino, branco e letrado -, é possível compreender, com relativa facilidade, as razóes pelas quais as mulheres, em vez de assumirem o papel de sujeito, ficaram relegadas à função de objeto do discurso nacionalista literário, sendo "desde sempre destituídas da condição de sujeitos históricos, políticos e culturais, [elas] jamais foram imaginadas e sequer convidadas a se imaginarem como parte da irmandade horizontal da nação" (SCHMIDT, 2000, p. 86).Ao colocar a questão nesses termos, o pensamento de Rita Schmidt dialoga com o trabalho de diferentes teóricas e pensadoras feministas, como Mary Louise Pratt, Doris Sommer e Jean Franco. Ao discutir o papel relegado à figura feminina no processo de narração da nação, Mary Louise Pratt (1994) demonstra, a partir de uma leitura crítica das concepçôes de Benedict Anderson (1989), como a Literatura reforçou uma ideia bastante presente no discurso constitutivo das naçôes latino-americanas resultantes da descolonização ocorrida no século XIX, qual seja, a de que o feminino pertencia à esfera doméstica, não sendo legítima a sua presença na esfera pública da "fraternidade" que imaginava e construía a nação. Em sua análise de obras que relacionam a esfera amorosa e doméstica com as questôes políticas nacionais, a visão de Pratt (1994) filia-se à leitura de Doris Sommer (1994), que sublinha o fato de textos literários canônicos dos países latino-americanos, dentre os quais o romance O Guarani, do brasileiro José de Alencar (2001),configurarem histórias de amor. Na mesma direção vai Jean Franco (1994), ao destacar o papel que a mulher deveria desempenhar segundo o discurso da elite que estava à frente do processo de construção da identidade nacional dos nascentes estados latino-americanos.

Náo obstante o fato de as mulheres terem historicamente desempenhado quase que exclusivamente o papel de personagens nos textos literários de autoria masculina - muitas das quais se tornaram emblemáticas para a construção de uma ideia de Brasil, dentro e fora das fronteiras nacionais, haja vista os casos das mulheres dos romances urbanos do já mencionado Alencar $(1981 ; 1998)$ e as erotizadas figuras femininas da obra de Jorge Amado (1979; 1987) -, sendo alijadas, por parte da crítica e da historiografia literária, do processo de elaboração dessa narrativa da nação, o trabalho das pesquisadoras feministas, ao longo das últimas décadas, tem contribuído não apenas para o resgate de importantes escritoras brasileiras do século XIX, cuja voz e obra foram silenciadas, mas também para, a partir do estudo do texto dessas mulheres, promover o que Sandra Gilbert (1986) denomina revisionary imperative, ou seja, uma revisão, reestruturação e 
reelaboração dos pressupostos que orientam o pensamento patriarcal e, por extensão, o cânone literário constituído a partir das premissas que sustentam tal pensamento. Semelhante é o pensamento de Rita Schmidt (1999), ao ressaltar que o resgate das obras de autoria feminina escritas no Brasil oitocentista não só recupera uma memória recalcada pelo cânone, reagindo à opressão e ao silenciamento impostos pelo discurso crítico e historiográfico patriarcal, mas também revela outras narrativas da nação, que questionam as bases ideológicas do projeto literário brasileiro e ressaltam o caráter heterogêneo dessa comunidade imaginada. Nesse sentido, Rita Schmidt (1999) reforça que:

\begin{abstract}
Particularmente nas obras resgatadas de escritoras brasileiras do século XIX, tem-se observado que elas, a par de suas dificuldades em esclarecer sua autoridade discursiva - a função autoral está associada à identidade do autor como pai do texto, aquele que detém a prerrogativa da voz -, problematizam o código representacional das personagens femininas, operando deslocamentos semânticos significativos nos scripts convencionados pelo corpus de uma tradiçấo que se fixou na centralidade da perspectiva masculina. Tais deslocamentos abrem espaços de resistência, de não submissão dos textos à coerção ideológica dos scripts impostos pelo contexto históricosocial e pelos valores estéticos da época em que os mesmos foram produzidos (SCHMIDT, 1999, p. 37).
\end{abstract}

Contudo, como bem lembra a autora, em diversas oportunidades, a resistência a essa proposta de revisáo das premissas do pensamento que moldam nosso cânone literário - a qual muitas vezes assume um tom ofensivo que busca, dentro e fora da academia, invalidar, quando náo ridicularizar, a crítica literária de viés feminista -, longe de desestimular as pesquisadoras e os pesquisadores da área, acaba por servir de incentivo a tal tarefa, uma vez que, por entre as brechas desse esforço em desvalorizála, deixa transparecer a relevância dessa discussão não apenas na esfera das investigaçóes científicas, como também, e principalmente, no espaço de sala de aula.

\title{
Problematizando e ampliando o cânone em sala de aula
}

Ao discutir a questão do cânone literário, Douwe Fokkema e Elrud Ibsch afirmam que as obras que o compóem realizam uma tarefa importante no sistema literário ao qual pertencem, sendo "instrumentos' para a solução de problemas", na medida em que oferecem "matrizes de perguntas e respostas possíveis" (FOKKEMA; IBSCH, 2006, p. 51). Partindo dessa premissa, de 
que as obras consideradas canônicas podem ser vistas como um repertório de perguntas e respostas para questôes relevantes em determinado recorte social e histórico - uma ideia que, em larga medida, se aproxima da reflexão levada a cabo por Antoine Compagnon -, uma mudança no contexto de recepção faz com que não apenas se atualizem os critérios que norteiam a emissão do juízo de valor, conforme referido por Ginzburg, mas também que surjam novas perguntas e se exijam novas respostas, ocorrendo, dessa forma, inclusóes e exclusóes no cânone. Nesse sentido, segundo Fokkema e Ibsch (2006, p. 60), "o ajuste de um cânone vai certamente acontecer se existir uma diferença considerável entre o conhecimento transmitido pelo cânone e o conhecimento que é necessário e está disponível em textos não canonizados".

A eclosão dos movimentos sociais, que ganharam força a partir da segunda metade do século XX, e a consequente visibilidade conquistada pelos sujeitos postos à margem pelo discurso hegemônico representaram, sem sombra de dúvidas, algo nos moldes da mudança de paradigma referida por Fokkema e Ibsch (2006). Na esteira desse raciocínio, torna-se bastante coerente que as demandas por visibilidade e por autonomia de discurso não só por parte das mulheres - tenham, como consequência, uma discussão dos parâmetros que regem a concepçáo patriarcal e elitista de literatura e, por conseguinte, o redimensionamento do conjunto de obras literárias que corporificam tal concepçáo. Em um movimento diametralmente oposto à noção homogênea e idealizada de cânone, uma perspectiva emancipatória de educaçáo deve colocar em relevo a disputa inerente a todo e qualquer processo de construçáo de uma identidade coletiva, uma tensão que, por óbvio, náo pode ser apagada nos produtos culturais que provêm desse contexto e que, como uma via de mão dupla, o simbolizam ao mesmo tempo em que são por ele construídos. Seguindo tal linha de pensamento, a crítica literária de matriz feminista apresenta valorosa contribuiçáo para uma discussão mais aprofundada sobre literatura brasileira em sala de aula, tanto no âmbito da Educaçáo Básica quanto na esfera das licenciaturas em Letras, não por apresentar uma "outra literatura" (produzida por mulheres), mas por oportunizar uma releitura da Literatura Brasileira em seu conjunto, vista agora como algo mais amplo e mais complexo, a partir do diálogo que se estabelece entre essas duas experiências de ser brasileiro: a da autoria masculina e a da autoria feminina. Nesse sentido, valendo-me das palavras de Luiza Lobo (1999), parece plausível afirmar que: 
No aprofundamento teórico das questôes feministas, podem-se enfatizar os aspectos dialógicos necessários a uma negociaçẫo entre as partes interessadas no jogo social [...]. Precisa se articular, na sua constante ambiguidade com o termo différance, de Lacan. Nesta articulaçâo haveria um diálogo entre a ideia simples de margem, de diferente, de ambíguo, com a noção de dialogia, a que chamei de superação do pensamento aristotélico, cartesiano e metafísico da sociedade. Nas palavras de Wolfgang Iser, deve haver uma "coexistência do mutuamente exclusivo". Isto vem a ser a suspensão da lógica do terceiro excluído aristotélica, segundo a qual algo ou é certo ou é errado, alternativamente (A ou B), sendo os dois termos mutuamente excludentes, de modo absoluto. Tal dicotomia, alicerçada na construção metafísica ocidental, já não corresponde à ideia que fazemos de verdade e de universal na sociedade (LOBO, 1999, p. 48).

Tendo em mente a proposição da referida autora, parece-me que uma postura pedagógica emancipatória, preocupada com a formação de leitoras e leitores críticos, deve considerar a autoria feminina náo como algo à parte, uma espécie de "contracânone", e sim como algo integradoao sistema literário brasileiro de forma orgânica, como fonte de discussão e de problematizaçáo do corpus e das premissas que o constituem, como elemento de ampliaçáo e complexificaçáo do espectro da chamada literatura nacional. Nesse sentido, a ideia é muito mais propor uma leitura do cânone a contrapelo, preenchendo as lacunas e os "não ditos", do que segmentar a produção de autoria feminina, como se fosse algo que se encontra apartado da "Literatura" (pura e sem adjetivos), muito embora, cumpre frisar, seja justamente o fato de as obras escritas por mulheres materializarem particularidades formais e temáticas, decorrentes da experiência específica do gênero, o que faz com que tais textos configurem um elemento de tensão e desestabilização do caráter pretensamente homogêneo do cânone.

A essa altura da reflexáo aqui desenvolvida, peço licença para um relato pessoal que, acredito, contribui para ilustrar as questóes postas em discussão nestas páginas. Em sala de aula, nas disciplinas de Literatura dos cursos de licenciatura em Letras, gosto de instigar as alunas e os alunos perguntando, em termos cronológicos, qual a primeira mulher apresentada nas aulas de Literatura. Em geral, o nome de Clarice Lispector é recordado de pronto. Não raro, Cecília Meireles e Rachel de Queiroz são mencionadas como escritoras que antecederam a autora de A paixáo segundo GH. "Bom", digo eu invariavelmente, "Cecília e Rachel pertencem à chamada segunda geração do Modernismo brasileiro, também conhecida como geração de 30". E complemento: "Vocês acham que nenhuma mulher publicou antes da década de 30 do século passado? Acham que, dentre as obras literárias escritas por mulheres ao longo do século XIX, nada tinha 
qualidade suficiente para ser considerado digno de ser estudado na escola? $\mathrm{E}$, se tinha, por que esses textos não são mencionados em aula e não constam nos manuais de literatura nem nos livros didáticos?”.

Embora os nomes dessas mulheres tenham sido ocultados pela pena dos grandes críticos e historiadores da nossa literatura, procuro mostrar às turmas que muitas das obras de autoria feminina produzidas nos séculos XIX eXX não só apresentam valor (a partir do critério que orienta o juízo da crítica conservadora),mas também são leituras importantes por proporcionarem um outro olhar em relação aos parâmetros definidores do que seja literatura brasileira. É o caso do romance D. Narcisa de Villar, publicado em folhetim pela catarinense Ana Luísa de Azevedo Castro (2000), no jornal A Marmota, do Rio de Janeiro, em 1858, apenas um ano após a edição de $\mathbf{O}$ Guarani (ALENCAR, 2001). Embora ambos os romances compartilhem o mesmo tema, qual seja, a questão indianista romantizada na relação amorosa entre umaportuguesa e um indígena, o texto de Castro estabelece um contraponto interessante em relação ao de Alencar, não apenas por dar voz a uma figura feminina - designada apenas como "Taim" -, que relata a história que ouviu da índia Mãe Micaela, ao pé do fogo, em uma noite de inverno, subvertendo assim, em vários níveis, as premissas literárias patriarcais (a voz que narra é feminina e está intimamente ligada à matriz indígena e à tradiçáo oral), como também por apresentar uma visão crítica com relação ao projeto de naçáo idealizada levado a cabo pela literatura de Alencar. Sob esse aspecto, como bem ressalta Zahidé Lupinacci Muzart (2000a), a obra de Castro "É um romance sobre a opressão da mulher pela família e pela sociedade, e sobre a escravidáo dos índios pelos colonizadores. Aliadas, aparecem as denúncias ao machismo e ao racismo" (MUZART, 2000a, p.13). Diferentemente do projeto unificador de Alencar, materializado na alegoria do amor descrita por Doris Sommer (1994), a narrativa de autoria feminina oferece outra versão do processo de constituição da identidade nacional, na qual, como sublinha Rita Schmidt (2016, p. 256), "a possibilidade de miscigenação não significa redenção ou final feliz, mas desencadeia uma série de violências físicas e psicológicas, de modo que a família não é o lugar para alianças e satisfação amorosa".

Publicado no mesmo ano do livro de Ana Luísa de Azevedo Castro, Úrsula, da maranhense Maria Firmina dos Reis (2004), mexe com as bases de outro tema idealizado pela narrativa canônica do Romantismo brasileiro - a escravidão -, estabelecendo um contraponto à narrativa A escrava Isaura, de Bernardo Guimarães (1998), editada 16 anos mais tarde e equivocadamente apresentada como o primeiro romance abolicionista do sistema literário 
brasileiro. A exemplo do que se passa com a obra da escritora catarinense, o texto de Maria Firmina subverte a ideia de nação monolítica e sem fissuras sugerida pelos escritores canônicos, apresentando o sofrimento e as mazelas decorrentes do regime de escravidáo de uma maneira realista e contundente, em especial, a partir da figura feminina da Mãe Susana, uma velha escrava que configura um par opositivo importante à imagem da protagonista branca e aculturada de A escrava Isaura. Nesse sentido, tanto no caso de D. Narcisa de Villarquanto em Úrsula, as obras de autoria feminina, como bem observa Rita Schmidt:

[...] não só questionam o modelo de civilização e progresso alavancado pelo estado patriarcal colonial e seu regime escravocrata de produção e exploração, como também denunciam os mitos nacionais da miscigenação e da náo violência, trazendo à tona o reprimido da cultura, o sofrimento decorrente das relaçóes inter-raciais e da crueldade da família branca, representante da sociedade e do estado. Nem a mulher negra nem a mulher indígena jamais puderam ser modelos de refinamento, castidade e inocência cultivada dentro das quatro paredes da casa senhorial. Nesse sentido, ambos os romances projetam uma figuração sombria do projeto de construção da nação, o que constitui uma intervençáo no campo sociossemântico do que tem sido chamado de narrativas fundadoras da nacionalidade (SCHMIDT, 2016, p. 256).

Se as obras de Ana Luísa e de Maria Firmina oferecem um redimensionamento crítico de dois temas abordados por autores canônicos do Romantismo brasileiro, com o romance $\mathbf{A}$ rainha do ignoto, de Emília Freitas (2003), a problematização dos parâmetros críticos que sustentam o discurso historiográfico se dá pelo fato de a obra, escrita em plena vigência dos ideais positivistas, apresentar uma narrativa fortemente marcada pelo fantástico e pelo utópico. Publicada em 1899, mesmo ano da edição de Dom Casmurro, de Machado de Assis (1999), e nove anos após o surgimento de O cortiço, de Aluísio de Azevedo (1987), duas das obras mais emblemáticas dos principais autores do Realismo e do Naturalismo brasileiro, respectivamente, o texto de Emília subverte os ditames estilísticos da época e, fugindo das imposiçóes limitantes de um ideal de Literatura Brasileira moldada por preceitos da modernidade europeia, retoma elementos do romance utópico medieval, mesclando-os aos elementos do fantástico e do realismo mágico, agregando a eles uma reflexão e uma crítica à situação das mulheres no contexto social e familiar do final do século XIX. Nesse sentido, utilizando as palavras de Fani Miranda Tabak (2011), é possível dizer que nessa obra: 
A restituição da verdadeira função do imaginário torna-se uma estrutura de reconstrução histórica, calcada nas maravilhosas peripécias que elevam, deslocam e reposicionam os papéis e os lugares ocupados pelas mulheres no século XIX brasileiro. Nessa direçấo, podemos aproximar a narrativa de Freitas de uma espécie de gênero de transiçấo entre o fantástico (ou o estranho) e o realismo mágico, uma vez que este último reflete uma perspectiva profundamente crítica diante da história e de suas mazelas, especialmente na literatura hispano-americana (TABAK, 2011, p. 111).

Semelhante é o que se passa com o romance $\mathbf{O}$ perdáo, publicado em 1910 pela sul-rio-grandense Andradina de Oliveira (2010), que, além da ousadia de tratar o tema do adultério a partir da perspectiva da mulher, foi na contramão do regionalismo vigente - que tinha as figuras de Alcides Maia, de alta reputação à época, e de Simôes Lopes Neto, mais tarde incensado como o maior escritor da narrativa gauchesca, como os grandes autores do período - e ambientou sua trama no espaço urbano de Porto Alegre, que engatinhava no seu processo de modernização, antecipando, em 25anos, a obra dos canônicos Érico Veríssimo (1939) e Dyonelio Machado (2004), tidos como os iniciadores do romance urbano no Estado.

Do mesmo período é a produção da escritora carioca Júlia Lopes de Almeida, uma das figuras que talvez represente de forma mais emblemática a violência de gênero que marcou a construção do cânone literário brasileiro. Personalidade de renome no cenário intelectual do Rio de Janeiro no século XIX, com uma produção extensa e bastante apreciada à época, a autora participou ativamente do processo de criaçáo da Academia Brasileira de Letras, tendo, no entanto, a inclusão do seu nome vetada, sob a alegação de que, por seguir o modelo da Academia Francesa de Letras, a agremiação deveria ser constituída apenas por "homens de letras". A despeito dessa exclusão, a obra de Júlia Lopes de Almeida teve sua importância reconhecida recentemente, em especial, a partir da reediçáo de diversos de seus textos e do destaque dado, a partir da leitura crítica feminista, à problematização que seu trabalho literário oferece em relação à ideia de nação e de literatura nacional. Nesse sentido, como bem lembra Rita Schmidt, em A Silveirinha, romance de 1914, Júlia Lopes de Almeida discute o problema do estereótipo racial brasileiro:

[...] fazendo com que seu discurso aponte a ambivalência das alteridades por ele constituídas e enuncie o inconsciente da sociedade colonial brasileira, ou seja, uma cultura colonial transplantada náo há possibilidade de afirmar uma origem, mas tão somente diferenças. Diferenças essas que foram reprimidas na insistência de uma comunidade sem fissuras, em cuja representação Júlia Lopes de Almeida expôe a herança colonial e o trauma da violência simbólica perpetrada contra o outro (SCHMIDT, 2000, p. 96). 
Igualmente digno de nota, Memórias de Marta, publicado em 1888, antecipa-se a O cortiço (AZEVEDO, 1987)e discute, uma década antes do romance de Azevedo, o início da marginalização das classes menos favorecidas na cidade do Rio de Janeiro. No entanto, mais do que o mero caráter de primazia - o que, por si só, já questiona os parâmetros que orientam o discurso historiográfico conservador -, o texto de Júlia Lopes de Almeida propóe um novo olhar com relação ao discurso nacionalista que permeia as obras que constituem o cânone da Literatura Brasileira. Nesse sentido, como sublinha Rita Schmidt (2008a):

\begin{abstract}
Na comparação com $O$ cortiço, o que chama atenção é a diferença da relação entre narrador e o mundo narrado e a postura ideológica em relação às personagens. Em Memórias, um romance também concebido sob o influxo das teorias deterministas e positivistas que circulavam no período, as personagens são delineadas a partir de uma focalização caracterizada pela sensibilidade e pela solidariedade que coloca em relevo a situaçáo-limite em que vivem, as limitaçóes e os condicionamentos gerados num cenário cruel de desigualdades sociais, sem engessá-las em imagens estereotípicas, ao contrário de $O$ cortiço, em que o excesso de estereótipos indicia um regime discursivo que explicita o lugar social de onde fala o narrador, um lugar que detém o poder da voz e do olhar - e da avaliaçáo - na representação de um mundo visto como inferior (SCHMIDT, 2008a, p. 135).
\end{abstract}

Mais do que apenas reverter um equívoco decorrente das escolhas dos críticos e historiadores responsáveis por erigir o cânone nacional, o resgate e, principalmente, o debate das obras de autoria feminina, como se pode ler nas palavras de Rita Schmidt (2008a), possibilitam um olhar e uma postura mais críticos com relação aos conceitos de Literatura e naçáo brasileira. A experiência de gênero, aspecto que, como lembram Elaine Showalter (1994) e Hélène Cixous (1997), dentre outras pensadoras, desempenha uma função determinante no processo de escrita das mulheres, como não poderia deixar de ser, faz com que tais textos ofereçam uma outra visão, mais ampla, complexa e rica, de quem somos nós.

\title{
Referências
}

ALENCAR, José de. Lucíola. 7. ed. São Paulo: Ática, 1981.

O Guarani. São Paulo: Martin Claret, 2001.

Senhora. 31. ed. São Paulo: Ática, 1998. 
ALMEIDA, Júlia Lopes de. A Silveirinha. Florianópolis: Mulheres, 1997. Memórias de Marta. Florianópolis: Mulheres, 2007.

AMADO, Jorge. Dona Flor e seus dois maridos. 45. ed. Rio de Janeiro, São Paulo: Record, 1987.

. Gabriela, cravo e canela. 59. ed. Rio de Janeiro, São Paulo: Record, 1979.

ANDERSON, Benedict R. Naçáo e consciência nacional. São Paulo: Ática, 1989.

ASSIS, Joaquim Maria Machado de. Dom Casmurro. 37. ed. Sáo Paulo: Ática, 1999.

AZEVEDO, Aluísio Tancredo Gonçalves de. O cortiço. 18. ed. São Paulo: Ática, 1987.

BARTHES, Roland. Aula. 12. ed. São Paulo: Cultrix, 2004.

BAUMAN, Zygmunt. Modernidade líquida. Trad. Plínio Dentzien. Rio de Janeiro: Jorge Zahar, 2001.

CANDIDO, Antonio. Iniciaçáo à literatura brasileira. São Paulo: Humanitas, 1999.

CASTRO, Ana Luísa de Azevedo. D. Narcisa de Villar. 4. ed. Florianópolis: Mulheres, 2000.

CIXOUS, Hélène. The Laugh of the Medusa. In: WARHOL, Robyn R.; HERNDL, Diane Price. (Eds.) Feminisms: an anthology of literary theory and criticism. New Brunswick, New Jersey: Rutgers University Press, 1997. p. 347-362.

COMPAGNON, Antoine. Literatura pra quê? Trad. Laura Taddei Brandini. Belo Horizonte: UFMG, 2012.

DALCASTAGNÈ, Regina. Representaçôes restritas: a mulher no romance brasileiro contemporâneo. In: ; LEAL, Virgínia Maria Vasconcelos (Orgs.). Deslocamentos de gênero na narrativa brasileira contemporânea. São Paulo: Horizonte, 2010. p.40-64. 
DUARTE, Constância Lima de. Feminismo e literatura no Brasil. Estudos Avançados, São Paulo, v. 17, n. 49, p. 150-172, 2003.

FOKKEMA, Douwe Wessel; IBSCH, Elrud. Conhecimento e compromisso: uma abordagem voltada aos problemas dos estudos literários. Trad. Sara Viola Rodrigues, Patrícia Lessa Flores da Cunha, Priscila Canale e Fabiano Gonçalves.Porto Alegre: UFRGS, 2006.

FRANCO, Jean. Sentido e sensualidade: notas sobre a formação nacional. Trad. Cristina Cavalcanti. In: HOLLANDA, Heloisa Buarque de (Org.). Tendências e impasses: o feminismo com crítica da cultura. Rio de Janeiro: Rocco, 1994. p. 99-126.

FREITAS, Emília. A rainha do ignoto. Florianópolis: Mulheres; Santa Cruz do Sul: Edunisc, 2003.

GILBERT, Sandra M. What Do Feminist Critics Want? A Postcard from the Volcano. In: SHOWALTER, Elaine (Ed.). The New Feminist Criticism: Essays on Women, Literature, and Theory. London: Virago Press, 1986. p. 29-34.

GINZBURG, Jaime. Crítica em tempos de violência. São Paulo: EDUSP/ Fapesp, 2012.

GUIMARĀES, Bernardo. A escrava Isaura. Porto Alegre: L\&PM, 1998.

LIPOVETSKY, Gilles. Os tempos hipermodernos. Trad. Mário Vilela. São Paulo: Barcarolla, 2004.

LOBO, Luiza. A dimensão histórica do feminismo atual. In: RAMALHO, Cristina (Org.). Literatura e feminismo: propostas teóricas e reflexôes críticas. Rio de Janeiro: Elo, 1999.p. 41-50.

MACHADO, Dyonelio. Os ratos. São Paulo: Planeta do Brasil, 2004.

MOI, Toril. What Can Literature Do? Simone de Beauvoir as a Literary Theorist. PMLA, New York, n. 124, v. 1, p.189-198, 2009.

MUZART, Zahidé Lupinacci. Uma precursora: Ana Luísa de Azevedo Castro. In: CASTRO, Ana Luísa de Azevedo. D. Narcisa de Villar. 4. ed. Florianópolis: Mulheres, 2000. p. 5-15.

. (Org.). Escritoras brasileiras do século XIX: antologia. v. I. 2. ed. rev. Florianópolis: Mulheres; Santa Cruz do Sul: Edunisc, 2000. 
. (Org.). Escritoras brasileiras do século XIX: antologia. v. II. Florianópolis: Mulheres; Santa Cruz do Sul: Edunisc, 2004.

OLIVEIRA, Andradina de. O perdáo. Florianópolis: Mulheres, 2010.

PRATT, Mary Louise. Mulher, literatura e irmandade nacional. Trad. Valéria Lamego. In: HOLLANDA, Heloisa Buarque de (Org.). Tendências e impasses: o feminismo com crítica da cultura. Rio de Janeiro: Rocco, 1994. p. 127-157.

REIS, Maria Firmina dos. Úrsula. Florianópolis: Mulheres/Belo Horizonte: PUC-Minas, 2004.

SCHMIDT, Rita Terezinha. Recortes de uma história: a construção de um fazer/saber. In: RAMALHO, Cristina (Org.). Literatura e feminismo: propostas teóricas e reflexóes críticas. Rio de Janeiro: Elo, 1999. p. 23-40.

. Mulheres reescrevendo a nação. Estudos Feministas, Florianópolis, v. 8, n. 1, p. 84-97, jan./jun. 2000.

Centro e margens: notas sobre a historiografia literária. Estudos de literatura brasileira contemporânea, Brasília, n. 32, p. 127-141, jul./dez. $2008 a$.

Quem reivindica a identidade? Desenredo (Revista do Programa de Pós-Graduação em Letras da Universidade de Passo Fundo), v. 4, n. 1, p. 49-60, jan./jun. 2008b.

. Entrevista concedida a Jaime Ginzburg. Teresa (Revista de Literatura Brasileira), São Paulo, n. 17, p. 251-264, jan./jun. 2016.

SHOWALTER, Elaine.A crítica feminista no território selvagem. Trad. Deise Amaral. In: HOLLANDA, Heloisa Buarque de (Org.). Tendências e impasses: o feminismo com crítica da cultura. Rio de Janeiro: Rocco, 1994. p. 23-57.

SOMMER, Doris. Amor e pátria na América Latina: uma especulação alegórica sobre sexualidade e patriotismo. Tradução Maria Luiza X. de A. Borges. In: HOLLANDA, Heloisa Buarque de (Org.). Tendências e impasses: o feminismo com crítica da cultura. Rio de Janeiro: Rocco, 1994. p. 158-183. 
TABAK, Fani Miranda. Fronteiras na história literária: fantástico e utopia em A rainha do Ignoto. Letras de Hoje, Porto Alegre, v. 46, n. 1, p. 104111, jan./mar. 2011.

VERÍSSIMO, Érico. Caminhos cruzados. 3. ed. Porto Alegre: Globo, 1939.

Rafael Eisinger Guimarães <guimaraes@unisc.br> Recebido: 28/04/2017 Aceito: 05/09/2017 